\title{
RESEÑAS
}

Mapi Rivera, El sentido numinoso de la luz. Aproximaciones entre creación y experiencia visionaria, Herder, Barcelona, 2018. ISBN: 9788425441431.

\section{Haris Papoulias}

Proyecto de investigación HERCRITIA-UNED, Madrid

La luz ha sido siempre uno de los temas más hermosos e importantes de la historia del pensamiento, ya científico ya filosófico. A diferencia de muchos temas contemporáneos de investigación, que se presentan de manera forzada como "interdisciplinares", la luz es, por excelencia, un campo de estudio interdisciplinar. Artistas, filósofos, teólogos y científicos, disponen de una rama especifica dentro su propia disciplina dedicada al estudio de la luz. Se trata de uno de los pocos objetos del pensamiento que aún mantiene su sublimidad, a pesar de su proximidad y de su presencia en cualquier aspecto de nuestras vidas, desde el "cielo estrellado" de Kant, hasta las fibras ópticas de nuestras conexiones a Internet. Incluso en relación con objetos banales, la luz es algo esencialmente sublime, porque nunca se agota en los usos que suelen dársele, como tampoco en aquellas definiciones que algunas de las mejores mentes de la humanidad han intentado darle.

El misterio más profundo de la luz reside precisamente en el hecho de que debería ser lo más conocido, pues todo lo vemos gracias a ella, pero sin embargo a ella misma, y en sí misma, no la vemos, como Rivera subraya frecuentemente retomando afirmaciones de distintos autores. Aún menos conocemos su naturaleza; más bien, es la naturaleza la que se conoce gracias a la luz, latiendo ésta en sí misma siempre más allá de la mirada. Ésta es otra paradoja muy propia de la luz: la condición de visibilidad, queda en sí misma invisible.

No sorprende entonces que, más allá de sus empleos tecnológicos, la luz sea uno de los temas favoritos de toda mística, tanto de aquella relacionada con la religión, como de aquella otra relacionada con el arte y que durante siglos ha ofrecido una expresión privilegiada a los fenómenos "numinosos", según terminología de la autora. Continuando con las paradojas de la luz, podríamos decir que este libro, a pesar de muchas referencias relacionadas con ambientes históricos y culturales distintos, trata fundamentalmente del aspecto más oscuro de la luz: el que fomenta las experiencias 
místicas, chamánicas y de lo "sagrado" en el sentido más amplio posible. Su ventaja (que fácilmente puede volverse en desventaja fatal) es precisamente este "sentido más amplio".

Si para acudir en ayuda del lector tuviese que presentar el índice de contenidos, debería decir en primer lugar, que no es nada fácil en espacio tan reducido como el de una reseña, pues el índice de este trabajo ocupa nada menos que once páginas. De todas formas, el lector interesado puede consultar la página web de la editorial Herder. Allí encontrará las primeras páginas del libro en formato digital. Por esta razón, tengo que limitarme en esta sección bibliográfica a algunos puntos significativos. En general, parece que todo el trabajo está dividido en tres grandes secciones temáticas: tras una larga introducción (pp. 1-114), la primera sección sería la que se intitula "el cuerpo de percepción" (pp.115-230), la segunda "el cuerpo de saber" (pp.231-330), y la tercera "el cuerpo de conocimiento" (pp.331-432?) - es de lamentar la falta de numeración de capítulos que nos impide una división rigurosa; de hecho, se puede solo intuir que es ahí donde acaba esta parte y donde empieza una larga conclusión (pp. 433-471).

Si tomamos en serio la naturaleza interdisciplinar de este tema, se puede entender bien lo importante que es la mirada del lector, lo que cada uno puede buscar aquí, y lo que de hecho se ha querido ofrecer al público con este libro. A pesar de la amplitud de sus contenidos, me enfrento a la posibilidad de dar un juicio erróneo, tan sólo porque mi expectativa se ha visto defraudada. Creo honestamente que he de admitir mi decepción desde el punto de vista de un tratamiento filosófico-estético. Como decía, quizás no fuese éste el propósito de la autora; por lo que no puedo hacer más que presentar unas objeciones, limitadas y debidas a la perspectiva que me imponen mis estudios. Por otra parte, tan solo puedo evocar otros campos temáticos tratados en este libro, que con toda probabilidad, se mostrarán de gran utilidad a otros investigadores.

Asimismo, he de admitir que este trabajo sería muy admirable en su totalidad, si se hubiera presentado simplemente como un ensayo paralelo a las actividades artísticas de su autora. Su lectura se hace más problemática si se repara en el hecho de que fue el fruto de una investigación doctoral, lo que genera expectativas de orden académico y no solo de gustos personales. Si solo se tratara de estos, es preciso atestiguar que la autora elige con mucha atención, y trata con una pasión aún mayor, autores a los que es preciso amar, y de los que no podemos ignorar su influjo, tanto en la cultura general, como en el ámbito específicamente estético. Hildegarda de Bingen, Ibn Arabi, Teresa de Ávila, Jacob Böhme et al. (pp.83-96) son algunos de los autores aquí tratados. De ellos la autora elige siempre, con cuidado y acertadamente, pasajes centrales de sus obras que sacan a la luz - nunca mejor dicho - la importancia de este tema. Pero, por otro lado, con frecuencia son tratados en poco más de media página (lo que explica parcialmente las once páginas de índice). Por eso, es natural si se quiere profundizar en cada uno de ellos, que esta extensión se haga problemática. 
Este trabajo es una enciclopedia sobre concepciones místicas de la luz o de experiencias vividas a través de ella por grandes poetas, pensadores y artistas en general. Quizás no debería pretender nada más. Sin embargo, cómo no esperar algo más sobre unos temas tan hermosos. Como por ejemplo cuando la autora habla de los "iconostasios", que según la doctrina de la iglesia ortodoxa (pp. 337 ss) son los limites visuales entre nuestro mundo y Dios. Para el estudioso de estos temas, resulta natural pensar en los debates bizantinos sobre la luz increada. Sin entrar en debates filosóficamente complicados, debemos pensar aquel evento numinoso que acontece cada año durante la Pascua ortodoxa, a saber, el descenso, sin intervención humana, de la luz sagrada a la capilla del Santo Sepulcro. Hago referencia a dichos acontecimientos, intentando acercarme a intereses que parecen propios de este trabajo, porque, naturalmente, el interés académico con relación a la luz sería bastante distinto. Lo que se espera de un tratado científico es averiguar dónde residen los problemas, reconstruir los argumentos, interpretar metódicamente las obras de arte o los textos empleados como fuentes y proponer soluciones razonadas. No sería dificil encontrar esto en los grandes interrogantes formulados por la historia del arte del último siglo. Desde el gran historiador del arte, Hans Sedlmayr (Das Licht in seinen künstlerischen Manifestationen, 1979), el problema más importante sería entender las diferencias entre los periodos artísticos con relación a la concepción, tanto espiritual como técnico-formal, de la luz y sus expresiones artísticas. Desde un punto de vista filosófico, habría igualmente mucho trabajo interesante que llevar a cabo: de las estéticas griegas hasta las medievales del siglo XIII; y desde los debates que provocaron las teorías de Newton hasta la reacción alemana (Goethe, Runge, para citar solo los más conocidos); de los primeros teóricos de la fotografía y del cine (Kracauer, Benjamin, Bálazs) hasta nuestros contemporáneos (Baudrillard, Nancy, Didi-Huberman y una infinitud de otros).

Destaca en este libro la figura del filósofo francés Merleau-Ponty que, aunque parece ser una de las referencias constantes en el texto, sorprendentemente no es tratado en relación con los problemas de la fenomenología (podemos mencionar por ejemplo a Conrad-Martius, alumno de Husserl que, en su Realontologie en 1923, ya abre camino hacia un tratamiento del color por una ontología de la luz y que muy pocos hasta ahora han estudiado). iSorprende que el fenomenólogo francés sea citado, en cambio, con relación a los chakras y a los chamanes! (p. 105). ¿Se podría afirmar que, puesto que la mística constituye el ámbito principal de este libro, no es correcto tratar autores como las que acabo de mencionar? Parecería natural. Pero podemos pensar que bastantes de los estudiosos que se han ocupado de mística hasta nuestros días han sido muy poco "ortodoxos" académicamente. Así, por ejemplo Aby Warburg y toda su escuela (Saxl, Panofsky e incluso Gombrich para quien prefiera los best seller). Todos ellos han trabajado sobre una gran cantidad de temas "místicos": astrología, magia, paganismo; pero lo han hecho según un método y debemos a sus métodos que actualmente podamos estudiar y comprender mejor gran parte del patrimonio artístico occidental. Es curioso que ninguno de ellos aparezca en este estudio, ni tampoco apenas 
nadie perteneciente a otras escuelas o métodos de investigación artísticas. A pesar de esto, hay que admitir que el libro trata autores que pueden enriquecer la perspectiva del lector, presentándole fuentes de disciplinas distintas a la propia, y a las que, con toda sinceridad, no le sería fácil llegar (normalmente quien estudia Merleau-Ponty no tiene idea de experiencias chamánicas).

No cabe dudar de la pasión de la autora y de las dificultades de un trabajo de tal envergadura; su implicación personal se percibe desde la primera página del libro y sus relatos personales e íntimos sobre la importancia de la luz, son también un testimonio de la autenticidad de este trabajo. Pero también es verdad que un estudio doctoral no puede ser acogido bajo la misma mirada con la que se recibe un diario o una novela. Debe permitírsenos, por lo tanto, cierta desconfianza, relacionada tan sólo con estos propósitos, que de ninguna manera ha de afectar a su valor literario, que escapa de nuestras competencias críticas.

Siguiendo con nuestro humilde oficio, otro ejemplo sobre la manera de acercarse a los textos, que a mi parecer tiene consecuencias a la hora de extraer conclusiones, sería la dependencia casi completa de traducciones castellanas. La autora presenta aproximaciones lingüísticas muy apresuradas. Por ejemplo cuando señala el hecho de que en "la palabra Dios o Zeus (!)" está implícito el mismo sentido de lo divino y de lo numinoso. Aunque no completamente equivocadas, afirmaciones como ésta, carecen de una base sólida de apoyo textual o interpretativo, como el que en este caso presta W. Burkert (Griechische Religion der archaischen und klassischen Epoche, 1977). Este autor, al fin y a cabo, estaría de acuerdo con una derivación lingüística de estos términos (que no es para nada tan explícita como pretende la autora). ¿Para qué sirve una referencia como esta? Serviría, quizás, para sacar una conclusión determinada y que falta por completo en el texto. Es decir, mientras que según la autora toda mística ha dicho lo mismo, simplificando: que Dios es Luz, lo que autores como el mencionado Burkert se preguntan tras muchas aclaraciones es cpor qué solo los griegos y los romanos (y no los hindúes, por ejemplo), elevaron esta divinidad (Zeus oJúpiter) a divinidad suprema de su panteón? No será porque la luz tiene un significado distinto y determinado, para Grecia/Roma y para Oriente? Y ¿qué decir de épocas y estudios todavía más complicados como los que se refieren a la antigüedad tardía y los cultos solares? ¿No es precisamente esta diferencia la que nos proporcionaría un conocimiento más acertado de unos y otros? Para decirlo con un autor citado en este estudio, Walter Otto, una mayor atención a la cultura griega nos habría hecho reparar en el hecho que los dioses griegos no son dioses del sol, o del rio o de algo, como se presentan en los dibujos animados, sino que son dioses individuales con determinaciones y atributos personales; algo que Otto luchó por aclarar, subrayando las diferencias, incluso con el panteón hinduista (véase su hermenéutica magistral en el capítulo sobre Hermes de su obra Los dioses de la Grecia). Naturalmente se trata de detalles, que, pero, pueden condicionar -y han condicionado- nuestra comprensión en dichos estudios. Y hablando de otros textos díscolos, como los que encontramos en la literatura sagrada de religiones orien- 
tales, que solo en los últimos años han empezado aparecer en traducciones castellanas fiables, la cuestión se podría hacer mucho más complicada. Así que la breve historia esbozada en las primeras cien páginas, nos deja bastante insatisfechos.

La "metafísica de la luz" (p.78) presenta un tema de máxima importancia en la historia de la filosofia, que en realidad es tratado como una "parapsicología de la luz" al hablar del resplandor de Jesús en términos similares a la iluminación de Buda (p.82). De nuevo quizás, nuestra incapacidad para comprender podría provenir de una especie de deformación profesional. Para que nos entendamos: lo que se esperaría como una "metafísica de la luz" propiamente dicha, sería algo así como la Piccola metafisica della luce del italiano S. Petrosino (2004) o el Das Philosophisce Licht und das Licht in der Kunst (1993) del alemán Hartmut Böhme. La Metafísica como disciplina filosófica no trata de experiencias personales, extracorporales, extáticas, etc., sino del ser y de sus atributos, es decir de diferencias determinadas.

Más adelante, se anuncia otro de los temas que podríamos suponer más importantes. Un tema que aparece muy raramente, incluso en estudios de muy alto nivel, que la luz no siempre es una metáfora (p. 83). Aquí vuelven a ser útiles las categorías de una verdadera metafísica de la luz, porque si no es metáfora, si no indica algo distinto, entonces ¿cuál es su propia naturaleza? Para eso sirven las categorías. Limitándonos a este mismo capítulo, se puede observar como en realidad no se hace otra cosa que hablar de la luz como si fuera una simple -aunque privilegiada- metáfora: "una nube de color de fuego" (p.90), "un torrente de luz" (p.91) etc.

Dejando a un lado las pretensiones de una filosofía sistemática, hay que señalar que indudablemente, la mejor parte de este trabajo es la que concierne el arte contemporáneo, donde se percibe la familiaridad de la autora con las obras de los artistas mencionados. Bill Viola, Olafur Eliasson, Jaume Plensa, Anish Kapoor, James Turrell (pp. 403-433) son los artistas que gozan de párrafos o capítulos dedicados a ellos. Es aquí donde la autora habría podido proporcionarnos su gran conocimiento sobre las manifestaciones artísticas de la luz en el arte contemporáneo, base indispensable para cualquier estudio sobre el sentido de la luz en ámbito artístico y en la cultura de nuestra época.

Nuestra mirada se aleja de la que nos ofrece la autora solamente cuando entramos en los detalles, en el tratamiento específico de cada cosa. Es cierto que las fuentes de cada artista son muy importantes a la hora de entender su obra. La cuestión, sin embargo, no es si estos artistas han leído los poemas de Juan de la Cruz, sino, en primer lugar, la determinación especifica que la luz adquiere en sus obras. El video arte no se eleva inmediatamente a arte religioso simplemente porque se han leído los textos de Dionisio Areopagita. Habría que preguntarse, por ejemplo: ¿es la luz artificial, empleada por el video arte, del mismo orden ontológico que la luz natural, empleada por una vidriera de una catedral gótica? Grandes estudiosos del arte sagrado, como Juan Plazaola (El arte sacro actual, 1965), ya hace décadas han explicado el daño 
profundo que sufre el sentido místico de la experiencia religiosa de la iglesia católica a causa de la introducción de la luz electica.

Si es verdad que nuestra relación con la luz condiciona no solo nuestra experiencia creativa y artística, sino toda nuestra existencia, como creo que también la autora de este libro tiene claro, entonces sería mucho más urgente hacer una crítica radical de esta luz y de cómo modifica nuestra percepción del mundo de manera pormenorizada. Sinceramente, no es suficiente para entender mejor la naturaleza de la luz o de nuestra propia mirada, el hecho de que Jacob Böhme dijese algo parecido a un maestro zen. Tampoco es suficiente añadir un relámpago con un software a una fotografía para crear una obra de arte sub specie lucis, como sí lo hizo la escuela de Skagen en Dinamarca (por poner de nuevo un ejemplo entre miles): silenciosamente, sin pretender hablar ni de Dios ni de cosas extravagantes.

No obstante, esta escuela nos ha dejado verdaderos tratados visuales sobre la luz - por no hablar de casos como el de El Greco o de Caravaggio, que sería mejor dejarlos impronunciables frente a la pobreza de lo que hoy sería la luz en las artes visuales.

Lo que quizás escapa a la atención, es que obras de arte nacidas en el mismo ambiente cultural de Jacob Böhme, por ejemplo, son simplemente incomprensibles siguiendo nociones que se refieren vagamente a la India o al Zen. De hecho, ¡sería una verdadera revolución que alguien lograse explicar la pintura de Cranach con teorías estéticas chinas! Pero ¿de verdad se puede hacer algo así? Y ¿por qué? ¿qué ganaríamos? Se puede estimar y admirar a otras civilizaciones por lo que son en sí mismas y no porque "han dicho lo mismo que nosotros". De hecho, un pluralismo acrítico no hace más que destrozar toda la especificidad por la que las civilizaciones han trabajado a lo largo de su historia. Si ahora pasáramos a nivel doctrinal deberíamos ser mucho más estrictos: la negación, por ejemplo, de la que hablan los japoneses, no tiene nada que ver con la teología apofántica de Dionisio, y lo mismo vale con respecto a su Dios (la primera palabra de la Theologia Mystica de Dionisio, recordémoslo, es Trinidad, y para entender cómo la Trinidad no es el Buda de la Tierra Pura y tampoco ninguna otra divinidad, quizás se deberían leer sus fuentes porque ahí se explica mejor: Basilio, Gregorio de Nisa, Gregorio Nacianceno, que sin embargo son mucho más aburridos que Castaneda u otros personajes parecidos. En fin, a nivel artístico, resulta todavía más desagradable tener que subrayar lo evidente: si alguien piensa que un iconostasio tiene que ver con la mística de la luz hindú, es que probablemente no sabe ni lo que son uno y otro.

Llego a preguntarme si soy yo quien se ha equivocado con esta lectura o si todo deriva simplemente de un error de la librería que colocó este libro entre las novedades en filosofía y en estética, atrayendo así nuestro interés. ¿Qué se propone este libro? Las "indicaciones al uso" se presentan muy tarde (y por Josep Maria Jori), en p. 468, al final del libro. Ahí podemos leer, por fin, que "no hemos escrito un libro sobre la representación de la luz o de cómo se trata la luz en las imágenes" (que, 
según mi humilde opinión, es lo único que debería hacer un estudioso del arte); la lista de negaciones continúa y tras haber excluido la reflexión estética, la psicología de la percepción y también la "creación y espiritualidad", concluye que "consideramos la vía chamánica, mística y transpersonal como procesos orgánicos similares al de la persona creadora; sin embargo, destacamos la capacidad de esta última para traducir y fijar la experiencia de «visión» que todas ellas comparten." Otra vez más, la palabra «visión» esta empleada no como visión determinada, por ejemplo, según los diversos tipos de perspectiva que podrían explicar las diferencias efectivas de la mirada en la historia. ¿Cómo entonces? Cuatrocientos paginas antes, el comienzo del libro ya había anticipado de algún modo este resumen. En palabras de la autora "la hipótesis de este libro es que la «visión» es imprescindible para que la creación devenga genuina, que el roce con lo numinoso es el germen de toda obra de arte, que si esta inspiración falta, la obra se limita a la especulación" (p.30). No podríamos estar más de acuerdo. Esta "inspiración" es la condición necesaria para la producción de la obra de arte - el problema es que no es también su condición suficiente, y para entender la diferencia entre una y otra, lamentablemente, sí que se necesita la especulación. 
